\title{
Aplicação de métodos de dimensionamento de pavimentos aeroportuários da FAA ao Aeroporto Internacional Presidente Juscelino Kubitschek
}

\author{
Bernardo Antonio Silva Ramos ${ }^{1}$, Dario Cardoso de Lima ${ }^{2}$, Heraldo Nunes Pitanga ${ }^{3}$, Taciano \\ Oliveira da Silva ${ }^{4 \bowtie}$
}

\author{
${ }^{1}$ Centro Universitário do Distrito Federal, Departamento de Engenharia Civil, bernardoramos@gmail.com \\ 2Universidade Federal de Viçosa, Departamento de Engenharia Civil, declima@ufv.br \\ 3Universidade Federal de Viçosa, Departamento de Engenharia Civil, heraldo.pitanga@ufv.br \\ 4Universidade Federal de Viçosa, Departamento de Engenharia Civil, taciano.silva@ufv.br
}

\section{Recebido:}

24 de junho de 2016

Aceito para publicação:

06 de julho de 2017

Publicado:

30 de dezembro 2017

Editor de área:

Jorge Barbosa Soares

\section{Palavras-chaves:}

Pavimento aeroportuário,

Dimensionamento,

FAARFIELD.

\section{Keywords:}

Airport Pavement,

Design,

FAARFIELD.

DOI:10.14295/transportes.v25i4.1180

\begin{abstract}
RESUMO
Neste artigo, aborda-se o dimensionamento da pista de pouso e decolagem 11R/29L, em pavimento flexível, do Aeroporto Internacional Presidente Juscelino Kubitschek, empregando-se os métodos de dimensionamento da Federal Aviation Administration (FAA) divulgados na AC 150/5320-6D, de 1995, e na AC 150/5320-6E, de 2009, considerando-se os tráfegos aéreos do dimensionamento original e aquele atualizado para o ano de 2013. Foi possível observar a sensibilidade do procedimento da FAA de 2009 no que diz respeito à obtenção de estruturas mais fiéis às solicitações impostas pelos tráfegos analisados. Em relação às estruturas obtidas, pode-se observar: (i) a espessura de projeto obtida com o emprego do programa computacional FAARFIELD v. 1.305, para o mesmo tráfego aéreo de projeto, foi $10 \mathrm{~cm}$ menor do que aquela determinada com o emprego do procedimento da FAA de 1995; (ii) a espessura de projeto oriunda da utilização do procedimento da FAA de 1995, mas empregando-se o tráfego aéreo atual, foi $2,5 \mathrm{~cm}$ maior àquela determinada empregando-se o tráfego aéreo original de projeto; e (iii) a espessura de projeto determinada com o programa computacional FAARFIELD v. 1.305 , considerando-se o tráfego aéreo atual, foi $21,5 \mathrm{~cm}$ menor do que aquela obtida com o emprego do procedimento da FAA de 1995.
\end{abstract}

\begin{abstract}
This article addresses the design of the flexible pavement runway $11 \mathrm{R} / 29 \mathrm{~L}$ of the International Airport Presidente Juscelino Kubitschek using the design procedures of the Federal Aviation Administration (FAA) published at the AC 150/5320-6D, in 1995, and at the AC 150/5320-6E, in 2009, considering the original design air traffic and that updated to the year 2013. It was possible to observe the sensibility of the FAA 2009 procedure in resulting on structures more reliable for the solicitations of the air traffic considered. Based on the results obtained, it was possible to observe: (i) the design thickness obtained with the use of the FAA 2009 procedure, for the same design air traffic, resulted is $10 \mathrm{~cm}$ lower than that determined with the use of FAA 1995 procedure; (ii) the design thickness determined using the FAA 1995 procedure, and the current air traffic was $2.5 \mathrm{~cm}$ higher than that determined using the original design air traffic; and (iii) for the current air traffic, the design thickness determined using the FAA 2009 procedure was $21.5 \mathrm{~cm}$ lower than that obtained with the use of the FAA 1995 procedure.
\end{abstract}

\section{INTRODUÇÃO}

Devido ao crescimento acentuado na demanda pelo uso de serviços aeroportuários no Brasil, houve uma necessidade crescente de investimentos para a manutenção da qualidade dos aeroportos. As concessões, através de parcerias público-privadas, vieram ao encontro dessas necessidades e tiveram como objetivo 
ampliar e aperfeiçoar a infraestrutura aeroportuária brasileira, promovendo melhorias no atendimento e nos níveis de qualidade dos serviços prestados aos usuários no transporte aéreo do país (INFRAERO, 2016). Com essa necessidade de investimentos na infraestrutura aeroportuária brasileira, surgiu também a necessidade de se desenvolverem estudos para a utilização de novos procedimentos para o dimensionamento de pavimentos aeroportuários que resultem em pavimentos mais adequados às solicitações impostas pelo tráfego aéreo.

Considerando-se a importância e o alcance do setor aeroviário para a economia do Brasil e o fato de que não há um método brasileiro de dimensionamento de pavimentos aeroportuários, buscou-se direcionar o presente trabalho para a apresentação de um estudo de caso relativo ao Aeroporto Internacional Presidente Juscelino Kubitschek, com o emprego dos procedimentos mais recentes da Federal Aviation Administration (FAA), dos Estados Unidos, para o dimensionamento de pavimentos aeroportuários flexíveis, que têm-se constituído na base de procedimentos adotados no Brasil nas últimas duas décadas, a saber: (i) AC 150/5320-6D (FAA, 1995); (ii) AC 150/5320-6E (FAA, 2009); e (iii) AC 150/5320-6F (FAA, 2016).

A circular AC 150/5320-6E (FAA, 2009) foi cancelada pela publicação da versão atual, AC 150/53206F (FAA, 2016). Entretanto, esta nova publicação, em resumo: (i) apresenta modificações no dimensionamento de pavimentos aeroportuários em consequência da atualização do programa computacional FAARFIELD para a versão 1.41; e (ii) mantém a filosofia de projeto apresentada na AC 150/5320-6E (FAA, 2009) que se baseia nos valores da tensão vertical máxima no topo da camada de subleito e da tensão horizontal máxima na parte inferior da camada de revestimento asfáltico, como elementos de previsão da vida útil do pavimento. Assim, basicamente, o procedimento possibilita o cálculo das espessuras das várias camadas do pavimento para suportar determinado conjunto de tráfego aeroviário ao longo do tempo, considerando-se a capacidade de suporte do subleito e das outras camadas do pavimento.

\section{MÉTODO DE DIMENSIONAMENTO DE PAVIMENTOS AEROPORTUÁRIOS NO BRASIL}

Taffe Júnior (2002) ressalta que, historicamente, o dimensionamento de pavimentos aeroportuários no Brasil é baseado nos métodos desenvolvidos pela FAA, seja no projeto de novos pavimentos, assim como na restauração de pavimentos deteriorados. Criada em 1958, a FAA é uma agência governamental ligada ao Departamento de Transporte dos Estados Unidos, que é responsável pelos regulamentos e por todos os aspectos relacionados à aviação civil daquele país. Através das suas publicações, entre várias outras funções, essa entidade orienta projetistas e administradores quanto ao dimensionamento de pavimentos aeroportuários.

Nas últimas décadas, os pavimentos aeroportuários brasileiros têm sido dimensionados de acordo com as metodologias desenvolvidas pela FAA que se encontram apresentadas nos documentos AC 150/5320-6C (FAA, 1978), AC 150/5320-6D (FAA, 1995), AC 150/5320-6E (FAA, 2009) e, recentemente, AC 150/5320-6F (FAA, 2016). Tem-se que a AC 150/5320-6E (FAA, 2009), com abrangência sobre pavimentos rígidos e flexíveis, veio substituir aquela divulgada na AC 150/5320-6D (FAA, 1995), que preconizava a determinação das espessuras dos pavimentos rígidos e flexíveis através do modelo analítico de Westergaard e pelo Método do CBR, respectivamente. Além disso, o dimensionamento do pavimento aeroportuário deveria obedecer a sequência apresentada na Tabela 1.

Com relação às aeronaves, trabalha-se com uma divisão das mesmas em seis grupos, sendo que o projetista seleciona e ajusta as frequências de pouso e decolagem e os pesos das aeronaves consideradas no tráfego aéreo do aeroporto. Caso haja a necessidade de se considerar um grupo de aeronaves que não estejam inseridas no programa, pode-se fazer esta consideração através de um grupo chamado Generic o qual possibilita a inserção da aeronave através do tipo de trem de pouso que ela possuir. 
Tabela 1: Etapas para o dimensionamento de pavimentos segundo a circular AC 150/5320-6D (FAA, 1995).

\begin{tabular}{ll}
\hline Etapa & Procedimento \\
\hline 1 & Identificar a aeronave de projeto como aquela que leve à maior espessura de pavimento. \\
\hline 2 & $\begin{array}{l}\text { Obter o peso máximo de decolagem e o tipo de trem de pouso da aeronave de projeto e de todas as outras aeronaves } \\
\text { que vão utilizar o aeroporto em questão. }\end{array}$ \\
\hline 3 & Obter o número de decolagens anuais previstas para cada aeronave. \\
\hline 4 & $\begin{array}{l}\text { Obter, para cada tipo de aeronave, a sua carga por roda como o resultado da divisão de 95\% do seu peso máximo de } \\
\text { decolagem pelo número de rodas do trem de pouso principal (ou dos trens de pouso principais, se aplicável). }\end{array}$ \\
\hline 5 & $\begin{array}{l}\text { Converter o número de decolagens de cada aeronave em termos da aeronave de projeto, considerando-se os fatores de } \\
\text { conversão de cada trem de pouso para o trem de pouso da aeronave de projeto. }\end{array}$ \\
\hline 6 & $\begin{array}{l}\text { Determinar o número equivalente anual de decolagens da aeronave de projeto com base no número de decolagens de } \\
\text { cada tipo de aeronave convertido para a aeronave de projeto e na relação entre as cargas por roda de cada aeronave e } \\
\text { da aeronave de projeto. }\end{array}$ \\
\hline $\begin{array}{l}\text { Empregar ábaco específico de projeto que relaciona o trem de pouso da aeronave de projeto, o tipo de pavimento (rí- } \\
\text { gido ou flexível), o peso máximo de decolagem da aeronave de projeto, a resistência mecânica do solo [através do valor } \\
\text { de CBR do subleito (pavimento flexível) ou do coeficiente de reação do subleito ou do sistema subleito/sub-base (pavim- } \\
\text { ento rígido)] e o número equivalente anual de decolagens da aeronave de projeto, para fins de determinação da } \\
\text { espessura do pavimento (espessura total de camadas de pavimento flexível ou da placa de concreto de pavimento rí- } \\
\text { gido). }\end{array}$ \\
\hline
\end{tabular}

\section{ESTUDO DE CASO}

O presente trabalho foi dirigido ao estudo de caso do dimensionamento estrutural do pavimento flexível da pista de pouso e decolagem 11R/29L do Aeroporto Internacional Presidente Juscelino Kubitschek, empregando-se os procedimentos que constam nas circulares AC 150/5320-6D (FAA,1995) e AC 150/5320-6E (FAA, 2009), considerando-se o tráfego aéreo original de projeto, datado de 2003, e aquele de 2013, que foi disponibilizado pela INFRAERO (2014). Especificamente, abordou-se: (i) o redimensionamento do pavimento original pelo procedimento contido no documento AC 150/5320-6E (FAA, 2009), (ii) o dimensionamento do pavimento para o tráfego aéreo atual pelo procedimento contido no documento AC 150/5320-6E (FAA, 1995) e (iii) o dimensionamento do pavimento para o tráfego aéreo atual pelo procedimento contido no documento AC 150/5320-6E (FAA, 2009).

\subsection{Dados técnicos sobre o Aeroporto Internacional Presidente Juscelino Kubitschek}

O Aeroporto Internacional Presidente Juscelino Kubitschek, também conhecido como Aeroporto de Brasília, está localizado na cidade de Brasília, Distrito Federal, Brasil. Sua inauguração data de maio de 1957. Atualmente, o aeroporto conta com duas pistas de pouso e decolagem, ambas em pavimento flexível, como segue: (i) pista 11L/29R, que data da época da construção do aeroporto, com 3.200 m de extensão, 45 m de largura e PCN (Pavement Classification Number) 76/F/B/X/T; e (ii) pista 11R/29L, mais recente, com $3.300 \mathrm{~m}$ de extensão, $45 \mathrm{~m}$ de largura e PCN 68/F/B/W/T (DECEA, 2015). Na Figura 1, apresentase o seu arranjo físico atual.

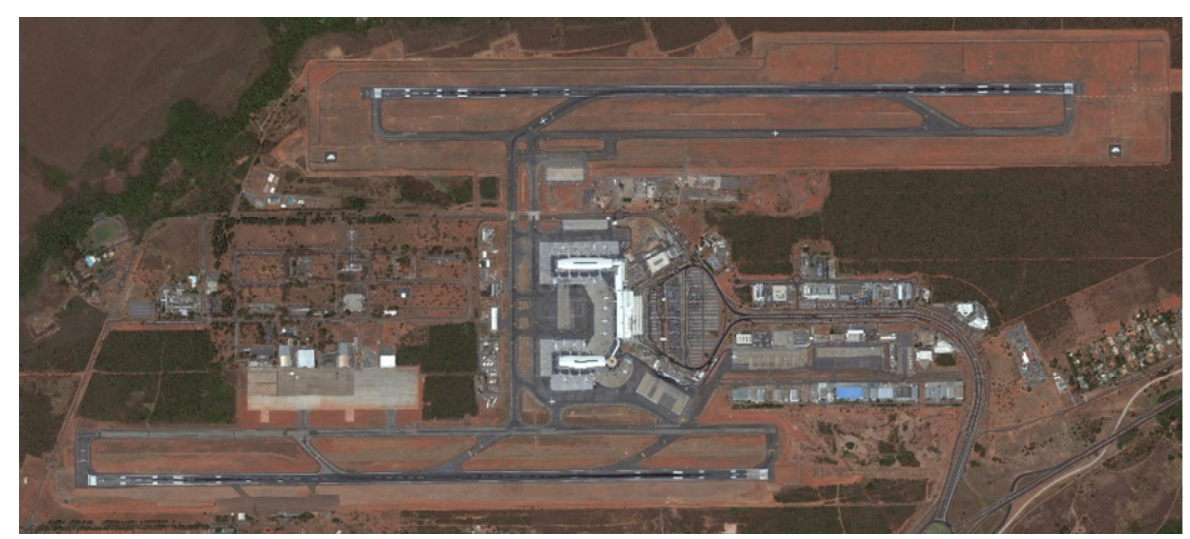

Figura 1: Pistas de pouso e decolagem 11L/29R (sup.) e 11R/29L (inf.) do Aeroporto Internacional Presidente Juscelino Kubitschek (GOOGLE, 2016). 
Segundo Araújo (2009), a pista 11R/29L, inaugurada em dezembro de 2005, teve sua estrutura dimensionada de acordo com a metodologia descrita na circular AC 150/5320-6D (FAA, 1995). Com relação à pista 11L/29R, não se dispõe de informação técnica sobre a sua composição e o correspondente procedimento de cálculo estrutural, o que levou o presente estudo a abordar apenas o dimensionamento da pista 11R/29L.

Farias e Falcão (2006 apud Araújo, 2009) informam que o projeto do pavimento da pista 11R/29L apresenta a seguinte constituição: (i) revestimento em Concreto Asfáltico (CA) com 6,0 cm de espessura; (ii) binder em CA com 8,0 cm de espessura; (iii) base em Brita Graduada Simples (BGS) granítica com 30 $\mathrm{cm}$ de espessura e CBR de 80\%; (iv) sub-base estabilizada granulometricamente com cascalho laterítico com espessura de $38 \mathrm{~cm}$ e CBR de 40\%; e (v) subleito regularizado com CBR de 12\%. Como não foi possível obter os valores dos Módulos de Resiliência (MR) das camadas utilizadas no pavimento, utilizou-se a Equação 1 (FAA, 2009) para a obtenção dos valores de MR, em MPa, em função dos valores CBR.

$$
\mathrm{MR}=10,34 \times \mathrm{CBR}
$$

Dessa forma, adotou-se valores de módulo de 124,11 MPa, 413,69 MPa e 827,37 MPa para as camadas de subleito, sub-base e base, respectivamente. Na Tabela 2, apresenta-se o tráfego aéreo de projeto considerado no dimensionamento da pista 11R/29L, tendo-se como aeronave de projeto a MD-11, conforme relata a Planorcon (2003 apud Araújo, 2009). Dados da INFRAERO (2014), apresentados na Tabela 3, abrangem o tráfego aéreo do Aeroporto Internacional Presidente Juscelino Kubitschek no ano de 2013.

Tabela 2: Movimento operacional considerado no projeto da pista 11R/29L (Araújo, 2009).

\begin{tabular}{ccccc}
\hline Aeronave & Peso máximo de operação $\mathbf{( k g )}$ & Carga por roda $\mathbf{( k g )}$ & Decolagem anual média & Trem de pouso \\
\hline B767-300 ER & 184.600 & 16.160 & 977 & \\
MD-11 & 285.100 & 16.160 & 900 & \\
B767-200 ER & 175.550 & 16.160 & 442 & Duplo Tandem \\
B757-200 & 115.700 & 14.543 & 294 & \\
A330-200 & 233.000 & 13.739 & 140 & \\
B757-300 & 122.470 & 16.160 & 116 & \\
A310-200 & 132.000 & 16.160 & 47 & Duplo-Duplo Tandem \\
\hline B747-100 & 340.100 & 16.160 & 1.328 & \\
B777-400 & 397.000 & 16.160 & 203 & \\
\hline B737-500 & 60.550 & 14.381 & 7.502 & Roda Dupla \\
A319-100 & 70.000 & 16.625 & 6.776 & \\
A320-200 & 73.500 & 17.456 & 6.024 & \\
B737-700 & 70.080 & 18.766 & 5.158 & \\
B737-800 & 79.015 & 15.675 & 3.858 & 2.164 \\
B737-300 & 63.300 & 16.644 & 296 & Triplo tandem \\
B737-200 & 52.400 & 12.445 & 128 & \\
\hline B777-200 & 300.600 & 16.160 & & \\
\hline
\end{tabular}

\section{RESULTADOS E DISCUSSÕES}

\subsection{Redimensionamento do pavimento flexível original pelo procedimento contido no documento AC 150/5320-6E (FAA, 2009)}

Nessa etapa, realizou-se o redimensionamento da pista original em pavimento flexível, empregando-se o procedimento relatado na AC 150/5320-6E (FAA, 2009), tendo como elementos de entrada no programa computacional FAARFIELD v. 1.305 o tráfego aéreo do ano de 2003 e os valores dos MR dos materiais que compõem as camadas do pavimento de projeto da pista 11R/29L. Em relação ao tráfego, para fins de redimensionamento do pavimento, foram considerados os pesos relatados no projeto original do pavimento, com a finalidade de se obter um resultado mais fidedigno.

Com o emprego do programa computacional FAARFIELD v. 1.305, obteve-se uma estrutura total de pavimento da ordem de $72 \mathrm{~cm}$, conforme pode ser visualizado na Tabela 4. Nota-se, também, que foi obtida uma espessura total menor para o pavimento resultante do redimensionamento realizado através 
do procedimento da FAA de 2009, comparativamente àquela considerada no projeto original do pavimento.

Tabela 3: Movimento operacional de 2013 do Aeroporto Internacional Pres. Juscelino Kubitschek (INFRAERO, 2014).

\begin{tabular}{ccccc}
\hline Aeronave & $\begin{array}{c}\text { Decolagem } \\
\text { anual média }\end{array}$ & Peso máximo de operação (kg) & Trem de pouso & Eixos adicionados \\
\hline C295 - Airbus CASA C 295 & 136 & 136.200 & 2 Rodas simples em Tandem & - \\
A332 - A330-200 & 418 & 231.107 & Duplo Tandem & - \\
B763 - B767-300 & 656 & 136.200 & \\
B752 - B757-200 & 685 & 116.120 & \\
B722 - B727-200 & 1.003 & 84.005 & \\
A321 - A321-100 & 1.336 & 83.400 & \\
B738 - B737-800 & 18.485 & 79.243 & \\
A320 - A320-200 & 21.922 & 73.900 & \\
B737 - B737-700 & 8.572 & 70.307 & \\
A319 - A319-100 & 7.784 & 64.400 & \\
A318 - A318-100 & 3.214 & 56.400 & \\
F100 - Fokker F100 & 3.608 & 45.813 & \\
E190 - Embraer E190 & 4.698 & 47.790 & \\
AT72 - ATR 72-210 & 2.265 & 21.500 & Dual Whl - 100 \\
E145 - Embraer ERJ 145 & 965 & 19.990 & \\
E135 - Embraer ERJ 135 & 1.487 & 19.000 & & Dual Whl - 45 \\
\hline
\end{tabular}

Em relação aos valores de MR considerados no dimensionamento realizado com o uso do programa computacional FAARFIELD v. 1.305, acredita-se que a variação na espessura total observada pode ser justificada pelas incertezas inerentes na conversão de dois índices que representam tipos diferentes de solicitações do solo, o que não exclui a influência do tráfego e a influência da mudança de metodologia no dimensionamento.

Nesse sentido, é necessário lembrar que, no método de dimensionamento publicado em 1995, empregou-se o conceito de aeronave de projeto, que é aquela que necessita da maior espessura de pavimento e que representa, de forma equivalente, todo o tráfego aéreo considerado no projeto, enquanto que, no método de 2009, trabalha-se com o conceito de mix de aeronaves, ou seja, no programa computacional FAARFIELD v. 1.305, leva-se em conta o tipo de trem de pouso, o peso máximo de decolagem e o número específico de decolagens de cada aeronave.

Tabela 4: Comparação entre as espessuras das camadas do pavimento original (FAA, 1995) e do pavimento redimensionado (FAA, 2009).

\begin{tabular}{ccc}
\hline Dados & Pavimento original & Pavimento redimensionado \\
\hline Revestimento asfáltico & $14 \mathrm{~cm}$ & $10 \mathrm{~cm}$ \\
Base & $30 \mathrm{~cm}$ & $20 \mathrm{~cm}$ \\
Sub-base & $38 \mathrm{~cm}$ & $42 \mathrm{~cm}$ \\
Espessura total & $82 \mathrm{~cm}$ & $72 \mathrm{~cm}$ \\
Versão do Método da FAA & 1995 & 2009 \\
Tráfego aéreo & \multicolumn{2}{|l}{$\begin{array}{l}\text { De projeto } \\
\text { De projeto }\end{array}$} \\
\begin{tabular}{c} 
Propriedades das camadas \\
\hline
\end{tabular}
\end{tabular}

Destaca-se que, no dimensionamento pelo método da FAA de 1995, a aeronave de projeto foi a MD11, com um número médio de 900 decolagens anuais, como é informado na Tabela 2 . Porém, no dimensionamento realizado com o uso do método da FAA publicado em 2009, a aeronave que apresentou maior contribuição para o CDF de projeto foi a B777-400, com maior peso operacional e número médio de 203 decolagens anuais. 


\subsection{Dimensionamento do pavimento asfáltico para o tráfego aéreo atual pelo procedimento AC 150/5320-6D (FAA, 1995)}

Realizou-se o dimensionamento do novo pavimento asfáltico com o emprego do procedimento descrito na AC 150/5320-6D (FAA, 1995), considerando-se o tráfego aéreo relativo ao ano de 2013 obtido junto à INFRAERO (2014) e denominado tráfego atual, apresentado na Tabela 2. Ressalta-se que, nesse dimensionamento, foram considerados os pesos das aeronaves apresentados como padrão no banco de dados do programa computacional FAARFIELD v. 1.305. 0 dimensionamento do novo pavimento asfáltico de acordo com a metodologia da FAA de 1995, denominado novo pavimento 1, foi dividido em três etapas, sendo elas: (i) definição da aeronave de projeto; (ii) obtenção do número de decolagens anuais equivalentes para a aeronave de projeto; e (iii) definição da espessura final do pavimento.

A Tabela 5 apresenta as espessuras totais de pavimento requeridas pelas aeronaves, considerandose um subleito regularizado com CBR de $12 \%$. Nessa tabela, os valores de espessuras totais de pavimentos foram obtidos por meio de ábacos que constam na AC 150/5320-6D (FAA, 1995). Em relação ao número de decolagens, os ábacos apresentam uma faixa de variação entre 1.200 e 25.000 decolagens. Assim, para movimentações superiores ou inferiores a esta faixa, os valores extremos foram considerados nos dimensionamentos. Os resultados obtidos foram comparados com os resultados obtidos na planilha de dimensionamento F806FAA.xls da própria FAA, na qual podem ser considerados números maiores de decolagens anuais. Com base nas espessuras resultantes apresentadas na Tabela 5, nota-se que a aeronave A332 foi a que necessitou de maior espessura do pavimento. Dessa forma, ela será considerada a aeronave de projeto para fins de dimensionamento.

Tabela 5: Espessuras do pavimento requeridas pelas aeronaves para um subleito com valor de CBR equivalente a $12 \%$.

\begin{tabular}{ccccc}
\hline Aeronave & $\begin{array}{c}\text { Número de } \\
\text { decolagens anual } \\
\text { médio }\end{array}$ & $\begin{array}{c}\text { Peso máximo de } \\
\text { operação }(\mathbf{k g})\end{array}$ & $\begin{array}{c}\text { EC 150/5320-6D } \\
\text { (FAA, 1995) }\end{array}$ & $\begin{array}{c}\text { F806FAA } \\
\text { (FAA, 1995) }\end{array}$ \\
\hline A332 & 418 & 231.107 & 66,0 & 74,9 \\
B763 & 656 & 187.502 & 55,9 & 63,1 \\
B752 & 685 & 116.224 & 44,5 & 47,0 \\
B722 & 1.003 & 84.081 & 53,1 & 50,7 \\
A321 & 1.336 & 83.475 & 53,1 & 51,5 \\
B738 & 18.485 & 79.314 & 61,5 & 62,3 \\
A320 & 21.922 & 73.967 & 59,7 & 60,0 \\
B737 & 8.572 & 70.370 & 53,8 & 54,4 \\
A319 & 7.784 & 64.458 & 50,8 & 50,8 \\
A318 & 3.214 & 56.451 & 45,2 & 48,0 \\
E190 & 4.698 & 47.790 & 44,5 & 43,6 \\
F100 & 3.608 & 45.854 & 41,9 & 41,6 \\
C295 & 136 & 136.200 & 40,6 & 24,0 \\
AT72 & 2.265 & 21.500 & 23,9 & 21,3 \\
E145 & 965 & 19.990 & 23,9 & 21,0 \\
E135 & 1.487 & 19.000 & 23,9 & \\
\hline
\end{tabular}

Além da limitação na abordagem do número correto de decolagens, houve, também, dificuldade em se considerar o peso das aeronaves do tráfego aéreo atual. Assim, na Tabela 6, têm-se as considerações adotadas para algumas aeronaves, em relação ao peso máximo de operação e ao tipo de trem de pouso. No caso da aeronave C295, por esta apresentar o mesmo tipo de trem de pouso que a aeronave C-130, optou-se por considerar, no dimensionamento, o ábaco específico para esta aeronave, mas utilizando-se o peso máximo apresentado no mesmo.

Após a definição da aeronave de projeto, o tráfego aéreo atualizado foi convertido em função do tipo de trem de pouso desta por meio do fator obtido pela Equação 2, o qual considera o número de rodas no trem de pouso principal da aeronave de projeto $(\mathrm{M})$ e aquele referente a aeronave a ser convertida $(\mathrm{N})$ (FAA, 2006). 


$$
\mathrm{F}=0,8^{(\mathrm{M}-\mathrm{N})}
$$

Tabela 6: Considerações realizadas para determinação da espessura total específica por aeronave

\begin{tabular}{|c|c|c|c|c|c|}
\hline Aeronave & $\begin{array}{c}\text { Peso máximo } \\
\text { de operação } \\
\text { (lb) }\end{array}$ & $\begin{array}{l}\text { Tipo do trem de } \\
\text { pouso }\end{array}$ & $\begin{array}{l}\text { Ábaco empregado } \\
\text { (AC 150/5320-6D) }\end{array}$ & Limitação & Consideração \\
\hline A332 & 509.047 & Duplo Tandem & Duplo Tandem & Peso máximo: $400.000 \mathrm{lb}$ & Peso: $400.000 \mathrm{lb}$ \\
\hline B763 & 413.000 & Duplo Tandem & B-767 & Peso máximo: $325.000 \mathrm{lb}$ & Peso: $325.000 \mathrm{lb}$ \\
\hline B752 & 256.000 & Duplo Tandem & B-757 & Peso máximo: $225.000 \mathrm{lb}$ & Peso: $225.000 \mathrm{lb}$ \\
\hline C295 & 300.000 & $\begin{array}{l}2 \text { Rodas simples } \\
\text { em Tandem }\end{array}$ & $C-130$ & $\begin{array}{l}\text { Não há ábaco específico } \\
\text { para este tipo de eixo }\end{array}$ & $\begin{array}{l}\text { Considerou-se o } \\
\text { ábaco da aeronave C- } \\
130 \text { e o peso de } \\
175.000 \mathrm{lb}\end{array}$ \\
\hline AT72 & 47.357 & Roda Dupla & Roda Dupla & Peso mínimo: $50.000 \mathrm{lb}$ & Peso: $50.000 \mathrm{lb}$ \\
\hline E145 & 44.031 & Roda Dupla & Roda Dupla & Peso mínimo: $50.000 \mathrm{lb}$ & Peso: $50.000 \mathrm{lb}$ \\
\hline E135 & 41.850 & Roda Dupla & Roda Dupla & Peso mínimo: $50.000 \mathrm{lb}$ & Peso: $50.000 \mathrm{lb}$ \\
\hline
\end{tabular}

A Tabela 7 apresenta os fatores obtidos para este dimensionamento, considerando-se a conversão em função do eixo da aeronave de projeto, isto é, eixo duplo tandem.

Tabela 7: Fator de conversão das decolagens anuais médias em função do trem de pouso da aeronave de projeto

\begin{tabular}{ccc}
\hline Aeronave considerada & Aeronave de projeto & Multiplicar as decolagens por: \\
\hline Duplo Tandem & & 1,0 \\
Roda Dupla & Duplo Tandem & 0,6 \\
2 Rodas simples em Tandem & & 0,6 \\
\hline
\end{tabular}

O número anual de decolagens convertido em função do tipo de trem de pouso da aeronave de projeto foi então convertido para o número equivalente de decolagens da aeronave de projeto, de acordo com a Equação 3 (FAA, 1995).

$$
\log R_{1}=\log R_{2} \times\left(\frac{W_{2}}{W_{1}}\right)^{1 / 2}
$$

em que: $\quad R_{1}$ : Equivalente anual de decolagens da aeronave de projeto;

$R_{2}$ : Decolagens anuais expressas em termos do trem de pouso da aeronave de projeto;

$W_{1}$ : Carga por roda da aeronave de projeto; e

$W_{2}$ : Carga por roda da aeronave a ser convertida.

A Tabela 8 apresenta o tráfego aéreo equivalente da aeronave de projeto obtido após as considerações já citadas. Através da Tabela 8, nota-se que, após definida a equivalência do número de decolagens entre o tráfego anual e a aeronave de projeto, houve uma redução de 77.234 para 63.141 movimentações.

Através do uso do mesmo ábaco e considerando-se o CBR da sub-base igual a 40\%, obteve-se uma espessura de $30 \mathrm{~cm}$, equivalente à espessura total das camadas de base e revestimento. Adotando-se a espessura mínima de revestimento asfáltico recomendada, de $10 \mathrm{~cm}$, obteve-se a espessura da camada de base de $20 \mathrm{~cm}$. A espessura da camada de sub-base foi então determinada, subtraindo-se o valor encontrado para a espessura das camadas de base e revestimento do valor da espessura total do pavimento. Consequentemente, obteve-se como espessura da camada de sub-base o valor de $50 \mathrm{~cm}$. Devido ao fato de se estar trabalhando com um número superior a 25.000 decolagens anuais, as espessuras encontradas foram corrigidas de acordo com os fatores de conversão apresentados na Tabela 9.

Por interpolação linear, considerando-se o total de 63.141 decolagens, obteve-se um acréscimo de 4 $\mathrm{cm}$ na espessura total do pavimento, sendo $2,5 \mathrm{~cm}$ adicionados na espessura do revestimento asfáltico e o restante adicionado proporcionalmente entre as espessuras da base e sub-base, conforme recomenda- 
ção da FAA (1995). Nesse caso, chegou-se à seguinte composição final do pavimento: revestimento asfáltico com 12,5 cm; base com $21 \mathrm{~cm}$; e sub-base com $51 \mathrm{~cm}$.

Tabela 8: Definição do tráfego aéreo equivalente da aeronave de projeto

\begin{tabular}{ccccccc}
\hline Aeronave & $\begin{array}{c}\text { Peso máximo } \\
\text { de operação } \\
\text { por roda (lb) }\end{array}$ & Trem de pouso & $\begin{array}{c}\text { Fator de } \\
\text { conversão }\end{array}$ & Decolagem anual média & \multicolumn{2}{c}{ Decolagens Equivalentes } \\
\cline { 6 - 8 } & 35.625 & Duplo Tandem & 1,0 & 418 & Duplo Tandem & A332 \\
\hline A332 & 35.625 & Duplo Tandem & 1,0 & 656 & 418 & 418 \\
B763 & 30.373 & Duplo Tandem & 1,0 & 685 & 656 & 415 \\
B752 & 43.945 & Roda Dupla & 0,6 & 1.003 & 642 & 1.313 \\
B722 & 43.629 & Roda Dupla & 0,6 & 1.336 & 855 & 1.757 \\
A321 & 41.454 & Roda Dupla & 0,6 & 18.485 & 11.830 & 24.752 \\
B738 & 38.659 & Roda Dupla & 0,6 & 21.922 & 14.030 & 20.895 \\
A320 & 36.780 & Roda Dupla & 0,6 & 8.572 & 5.486 & 6.300 \\
B737 & 33.689 & Roda Dupla & 0,6 & 7.784 & 4.982 & 3.940 \\
A319 & 29.504 & Roda Dupla & 0,6 & 3.214 & 2.057 & 1.036 \\
A318 & 25.000 & Roda Dupla & 0,6 & 4.698 & 3.007 & 820 \\
E190 & Roda Dupla & 0,6 & 3.608 & 2.309 & 574 \\
F100 & 23.966 & Duplo Tandem & 1,0 & 136 & 136 & 136 \\
C295 & 35.625 & Roda Dupla & 0,6 & 2.265 & 1.450 & 60 \\
AT72 & 11.247 & Roda Dupla & 0,6 & 965 & 618 & 33 \\
E145 & 10.457 & Roda Dupla & 0,6 & 1.487 & $\mathbf{7 7 . 2 3 4}$ & Total \\
E135 & 9.939 & & Total & $\mathbf{6 3 . 1 4 1}$ \\
\hline
\end{tabular}

Tabela 9: Acréscimo na espessura do pavimento para grandes números de decolagens (FAA, 1995)

\begin{tabular}{cc}
\hline Decolagens anuais médias & Correção da espessura do pavimento para decolagens superiores a 25.000 \\
\hline 50.000 & 104 \\
100.000 & 108 \\
150.000 & 110 \\
200.000 & 112 \\
\hline
\end{tabular}

\subsection{Dimensionamento do pavimento asfáltico para o tráfego aéreo atual pelo procedimento AC 150/5320-6E (FAA, 2009)}

Realizou-se o dimensionamento dos novos pavimentos asfálticos com o emprego do procedimento AC 150/5320-6E (FAA, 2009), considerando-se o tráfego aéreo atual, como apresentado na Tabela 2, e a mesma estrutura de camadas do pavimento conforme apresentado no item 3.1. Posteriormente, realizou-se a análise da influência da variação do período de projeto na estrutura final do pavimento asfáltico, considerando-se os períodos de projeto de 5, 10, 15 e 20 anos. Ressalta-se, também, que foram considerados os pesos das aeronaves apresentados como padrão no banco de dados do programa computacional FAARFIELD v. 1.305.

No dimensionamento do novo pavimento asfáltico, denominado novo pavimento 2, obteve-se uma espessura total de $63 \mathrm{~cm}$, o que resultou em uma estrutura menor do que aquela obtida para o pavimento original e todas as outras já dimensionadas no presente trabalho, como apresentado na Tabela 10.

Por terem sido projetados com o emprego do mesmo método de dimensionamento, segundo a FAA (1995), observa-se que o pavimento original e o novo pavimento 1 têm suas variações de espessuras justificadas pelas diferenças nos tráfegos aéreos considerados. Dessa forma, a diferença de espessuras observadas entre o pavimento original e o novo pavimento 1 justifica-se pelas características de tipo e número de movimentações referentes às aeronaves de grande porte. Vale ressaltar que as aeronaves MD-11 e A332, consideradas de fuselagem larga, foram aquelas de projeto, respectivamente, no caso dos tráfegos aéreos original e atual. 
Tabela 10: Comparação entre as espessuras das camadas do pavimento original, pavimento redimensionado e novo pavimento do Aeroporto de Brasília.

\begin{tabular}{ccccc}
\hline Dados & Pavimento original & $\begin{array}{c}\text { Pavimento } \\
\text { redimensionado }\end{array}$ & Novo pavimento 1 & Novo pavimento 2 \\
\hline Revestimento & $14 \mathrm{~cm}$ & $10 \mathrm{~cm}$ & $12,5 \mathrm{~cm}$ & $10 \mathrm{~cm}$ \\
Base & $30 \mathrm{~cm}$ & $20 \mathrm{~cm}$ & $21 \mathrm{~cm}$ & $20 \mathrm{~cm}$ \\
Sub-base & $38 \mathrm{~cm}$ & $42 \mathrm{~cm}$ & $51 \mathrm{~cm}$ & $33 \mathrm{~cm}$ \\
Espessura Total & $82 \mathrm{~cm}$ & $72 \mathrm{~cm}$ & $84,5 \mathrm{~cm}$ & $63 \mathrm{~cm}$ \\
Método da FAA & 1995 & 2009 & 1995 & 2009 \\
Tráfego aéreo & \multicolumn{2}{c}{ Ae projeto } & & Atual \\
\hline
\end{tabular}

No caso da diferença entre as espessuras do pavimento redimensionado e do novo pavimento 2, por terem sido dimensionados segundo a metodologia da FAA de 2009 e módulos de resiliência iguais, percebe-se a influência do tráfego aéreo na definição da espessura total do pavimento. Apesar de possuir um número maior de movimentações quando comparado ao tráfego aéreo de projeto, o tráfego aéreo atual não exigiu um aumento na espessura total do pavimento de acordo com a metodologia da FAA de 2009. Já em relação à estrutura do pavimento original, a diferença obtida na sua espessura $(82 \mathrm{~cm}) \mathrm{em}$ relação ao novo pavimento $2(63 \mathrm{~cm})$ evidencia, neste caso, a influência do refinamento da metodologia atual em relação à versão da FAA de 1995. Foi alcançado um valor unitário para o CDF de projeto e a aeronave mais representativa foi a B737-800.

Com vistas a se analisar a influência do período de projeto na estrutura do pavimento, realizaram-se outros três dimensionamentos, para os períodos de projeto de 5, 10 e 15 anos, conforme se apresenta na Tabela 11, já que 20 anos foi o período de projeto adotado nos dimensionamentos realizados.

Tabela 11: Comparação entre a espessura total do novo pavimento 2 quando de 5, 10, 15 e 20 anos

\begin{tabular}{lllll}
\hline \multirow{2}{*}{ Camada } & \multicolumn{4}{c}{ Vida útil (anos) } \\
\cline { 2 - 5 } & 5 & 10 & 15 & 20 \\
\hline Revestimento $(\mathrm{cm})$ & 10 & 10 & 10 & 10 \\
Base $(\mathrm{cm})$ & 20 & 20 & 20 & 20 \\
Sub-base $(\mathrm{cm})$ & 28 & 31 & 32 & 33 \\
Espessura total $(\mathrm{cm})$ & 58 & 61 & 62 & 63 \\
\hline
\end{tabular}

Através da Tabela 11, pode-se notar a redução na espessura total do pavimento ocasionada pela redução na sua vida útil. Obviamente, esperava-se que isso ocorresse, embora tenha causado surpresa a ocorrência de redução de apenas $5 \mathrm{~cm}$ na espessura para uma redução de 15 anos no período de projeto. Outra observação é a espessura da camada de base que foi mantida constante pelo programa nos dimensionamentos por considerar esta como espessura mínima de acordo com as aeronaves apresentadas no tráfego aéreo, havendo variação somente na espessura da camada de sub-base.

Todos os processos de dimensionamentos foram concluídos, resultando no mesmo CDF unitário de projeto. Este CDF é obtido para o topo do subleito. Por outro lado, foi possível observar uma diminuição do CDF do revestimento asfáltico, conforme é apresentado na Tabela 12. Os valores obtidos indicam que o revestimento estará em boas condições ao final da vida útil de projeto considerado.

Tabela 12: Variação do CDF do revestimento asfáltico do pavimento do Aeroporto Internacional Pres. Juscelino Kubitschek.

\begin{tabular}{ll}
\hline Vida útil (anos) & CDF do revestimento asfáltico \\
\hline 5 & 0,01 \\
10 & 0,01 \\
15 & 0,02 \\
20 & 0,03 \\
\hline
\end{tabular}




\section{CONCLUSÕES}

A disponibilidade de dados técnicos de projeto para o Aeroporto Internacional Presidente Juscelino Kubitschek possibilitou realizar uma análise das implicações da adoção dos procedimentos de projeto da FAA relatados na AC 150/5320-6D, de 1995 e na AC 150/5320-6E, de 2009. Assim, pode-se notar que o novo método da FAA de 2009, através da substituição dos ábacos de dimensionamento pelo uso do programa computacional FAARFIELD v. 1.305, facilitou o dimensionamento de novas estruturas de pavimentos, uma vez que é possível considerar um número maior de aeronaves sem limitação de pesos e movimentações. Além de permitir uma análise qualitativa, no dimensionamento, das implicações do tráfego aéreo e materiais utilizados nas camadas de pavimento.

A consideração do fator CDF, juntamente com a análise de camadas elásticas, no caso dos pavimentos flexíveis, possibilitou a obtenção de estruturas mais ajustadas às solicitações impostas pelo movimento operacional dos aeroportos. Fato este que poderá contribuir de maneira positiva e direta na gerência de pavimentos aeroportuários melhorando, por exemplo, o planejamento, a programação de investimentos, as obras de manutenção e a adoção de um cronograma mais eficiente de avaliações destes pavimentos.

Em relação às estruturas obtidas, é válido ressaltar que a comparação entre a estrutura do pavimento resultante do uso dos métodos da FAA de 2009 e 1995 deve ser feita com cautela uma vez que houve a necessidade de se converter os valores de CBR em MR para a utilização da metodologia da FAA de 2009 atribuindo incertezas na correlação. Reitera-se que esta conversão é prevista na circular AC 150/53206E e foi implementada automaticamente no programa computacional FAARFIELD v. 1.305.

Dessa forma, pode-se redimensionar o pavimento asfáltico original empregando-se a metodologia da FAA de 2009, obtendo-se uma espessura menor do que a adotada para o pavimento no projeto original, assim como dimensionar o novo pavimento 1, segundo a metodologia da FAA de 1995, mas considerando-se o tráfego aéreo atual. 0 que resulta em uma estrutura de pavimento de espessura maior do que aquela utilizada no pavimento original e no dimensionamento do novo pavimento 2 , segundo a metodologia de dimensionamento da FAA de 2009.

Em todos os dimensionamentos realizados, o CDF de projeto foi referente ao topo da camada de subleito e obteve-se valor unitário por ser esta a condição de projeto. Já o CDF do revestimento asfáltico pouco variou quando foi considerada a redução na vida útil do pavimento apresentando valores pequenos quando comparados ao CDF de projeto.

\section{AGRADECIMENTOS}

Os autores agradecem à CAPES, pela concessão de bolsa de estudo ao primeiro autor no decorrer de seu programa de mestrado desenvolvido junto ao Programa de Pós-Graduação em Engenharia Civil da UFV.

\section{REFERÊNCIAS}

Araújo, J.L. (2009) Características Funcionais e Mecânicas de Misturas Asfálticas para Revestimento de Pavimentos Aeroportuários. Dissertação de Mestrado em Engenharia Civil. Universidade de Brasília. Brasília, DF.

DECEA (2015) Carta de Aeródromo (ADC) - Brasília/Pres. Juscelino Kubitschek, INTL (SBBR). Departamento de Controle do Espaço Aéreo. Comando da Aeronáutica. Ministério da Defesa.

DNIT (2006) Manual de Pavimentação. Departamento Nacional de Infraestrutura de Transportes. Publicação IPR-719. Instituto de Pesquisas Rodoviárias. 3 ed. Rio de Janeiro, RJ.

FAA (2016) Airport Pavement Design and Evaluation - AC No. 150/5320-6F. Federal Aviation Administration. U.S. Department of Transportation. Washington, DC, USA.

FAA (2012) FAARFIELD 1.3 - Software Overview. Federal Aviation Administration. U.S. Department of Transportation. In: XI ALACPA Seminar on Airport Pavements and IX FAA Workshop. Santiago, Chile.

FAA (2009) Airport Pavement Design and Evaluation - AC No. 150/5320-6E. Federal Aviation Administration. U.S. Department of Transportation. Washington, DC, USA.

FAA (1995) Airport Pavement Design and Evaluation - AC No. 150/5320-6D. Federal Aviation Administration. U.S. Department of Transportation. Washington, DC, USA.

FAA (1978) Airport Pavement Design and Evaluation - AC No. 150/5320-6C. Federal Aviation Administration. U.S. Department of Transportation. Washington, DC, USA.

FAARFIELD (2010) Version 1.305. Washington, DC, USA: Federal Aviation Administration. Disponível em: http://www.airporttech.tc.faa.gov/DesktopModules/EasyDNNNews/DocumentDownload.ashx?portalid=0\&moduleid=37 08\&articleid $=4 \&$ documentid $=6$ 
GOOGLE Earth (2016) Version 7.1.5.1557. Google. Disponível em: https://www.google.com/earth/

INFRAERO (2016) Concessão de Aeroportos. Empresa Brasileira de Infraestrutura Aeroportuária. Disponível em http://www.infraero.gov.br/index.php/transparencia/concessao.html. Acessado em 2016.

ICAO (2004) Manual on the Regulation of International Air Transport - Doc. 9626. International Civil Aviation Organization

INFRAERO (2014) Movimento Operacional do Aeroporto de Brasília 2013. Empresa Brasileira de Infraestrutura Aeroportuária. Planilha EXCEL. Recebida em 2014.

Taffe Júnior. E. J. (2002) Uma Alternativa Econômica quanto ao Dimensionamento de Pistas de Aeródromos. Anais do VII Encontro de Iniciação Científica do Instituto Tecnológico da Aeronáutica, ITA. São José dos Campos, SP. 